\title{
La pandemia: ¿el acto final de Donald Trump?*
}

\author{
The pandemic: Donald Trump's last act?
}

\author{
Eric Carter \\ ' Professor, Geography Department/ \\ Macalester College. \\ Saint Paul - MN - USA \\ orcid.org/0000-0002-6766-1626 \\ ecarter@macalester.edu
}

Recebido em 26 ago. 2020. Aprovado em 19 set. 2020.
CARTER, Eric. La pandemia: ¿el acto final de Donald Trump? História, Ciências, Saúde - Manguinhos, Rio de Janeiro, v.28, n.1, jan.-mar. 2021, p.313-318.

\section{Resumen}

Se examina la gestión de Donald Trump, presidente de los EEUU, en la pandemia de covid-19.

Palabras clave: pandemia; Donald Trump (1946-); covid-19; EEUU, historia.

\section{Abstract}

This article examines President Donald Trump's handling of the covid-19 pandemic in the United States.

Keywords: pandemic; Donald Trump (1946-); covid-19; United States of America; history. 
$\mathrm{D}$ urante esta pandemia de covid-19 estamos pasando un momento extraordinario. Ya es sin duda la epidemia mejor documentada en la historia. Me refiero no solo al diluvio constante de noticias, sino también a la cantidad de comentarios, opiniones y perspectivas, de peritos, políticos y periodistas. Todos queremos agregar nuestra interpretación particular de la situación y quizás nos sentimos un poco presionados para dar sentido histórico a esta calamidad mundial, una tendencia que lamenta la escritora argentina Mariana Enríquez (18 abr. 2020).

Entonces, vacilo un poco en sumar una opinión más a las realizadas hasta ahora, especialmente cuando se trata de una situación tan dinámica y cambiante como la pandemia. Y aunque las causas de esta calamidad sean complejas y diversas (y las soluciones, muy difíciles), podríamos identificar algunos actores claves que tienen que hacerse responsables de esta situación. Así me limitaré a una examinación de la gestión de Donald Trump, presidente de los EEUU, frente a esta emergencia. Claro que él suele hacer y decir cosas inexplicables, inesperadas, inéditas e incoherentes. Esta costumbre de Trump ha sido siempre molesta y extraña, pero ahora su falta total de capacidad para responder coherentemente a la pandemia es algo muy serio, una amenaza al bienestar de mi país, los EEUU, y, me atrevo a decir, al del mundo entero.

¿Qué le pasa? ¿qué está haciendo? Tales preguntas precisan un resumen de su gestión ante la pandemia que nos sigue amenazando y un intento de explicar por qué se comporta de esta manera.

Aunque el coronavirus pandémico empezó a difundirse mundialmente en enero de este año, Trump, desde que llegó al poder en enero de 2017, ha desmantelado las instituciones que resguardan la seguridad sanitaria del país. Por ejemplo, recién llegado a la presidencia, despidió a una comisión de consejeros en problemas de bioética (creada por George W. Bush, y mantenida por Barack Obama) (Appel, 31 mayo 2019). Aunque no pudo eliminar al Affordable Care Act, conocido como Obamacare - la base legislativa de nuestro actual sistema de seguro médico - lo debilitó bastante con órdenes ejecutivas y maniobras fiscales (Simmons-Duffin, 14 oct. 2019). Trump nombró al actual secretario de Salud y Servicios Humanos, Alex Azar, principalmente por su postura en contra de Obamacare y su actividad previa como ejecutivo de la farmacéutica multinacional Eli Lilly.

Luego, en 2018, abandonó un programa de preparación para pandemias dentro del Consejo Nacional de la Seguridad (Sun, 10 mayo 2018). Y, como se relata en una investigación prolija, la administración de Trump cortó el presupuesto del CDC (Centers for Disease Control), una de las instituciones científicas más importantes del gobierno, y justamente la que se dedica a la investigación y control de brotes de enfermedades infecciosas (Sellers et al., 2020). Inclusive se redujo el grupo de delegados del CDC en China, de cincuenta a 14 personas, entre 2017 y 2020.

Gracias a estas decisiones, estábamos menos preparados que nunca para enfrentar una epidemia. En enero, el CDC se negó aceptar el kit de prueba para el Covid-19 que había creado la OMS. Para empeorar las cosas, la propia versión del kit del CDC sufría errores serios, una falla que retrasó la reacción del gobierno ante la epidemia (Yong, 4 ago. 2020). Además, en oportunidades reiteradas, Trump le restó importancia a los impactos de la epidemia, aún cuando se sintió obligado a declarar una emergencia nacional el 13 de 
marzo. Ese mismo día, lanzó una directiva confusa, la cual aparentemente suspendía todos los vuelos entre los EEUU y Europa inmediatamente (Yong, 4 ago. 2020). Pero fue solo un ejemplo más de reglamentos de control de fronteras en los que se mesclan innecesariamente las lógicas epidemiológicas y políticas, algo que Trump demostró, nuevamente en abril, con su declaración de la total suspensión de inmigración legal al país (Rogers, Shear, Kanno-Youngs, 20 abr. 2020).

Mientras tanto, sus pronunciamientos en Twitter y en las conferencias de prensa solo sirven para confundir más la situación, para producir un estado de desconfianza hacia el conocimiento científico y crear nuevos conflictos políticos y hasta querellas constitucionales. Trump da consejos médicos cuestionables, como su recomendación reiterada de tomar la hidroxicloroquina, terapia antimalárica, para prevenir la infección del covid-19. En otros momentos, cuestiona la eficacia de ciertas medidas recomendadas, como el uso de mascarillas. Se pone a discutir con su equipo de expertos, como el doctor Anthony Fauci, uno de los científicos más sabios de este gobierno, mundialmente reconocido por sus investigaciones sobre los virus, especialmente el VIH. Trump decidió prevenir que los científicos del CDC comunicaran directamente con el público, porque sus comunicados no coincidían con su visión de la pandemia (Yong, 4 ago. 2020). Y como ya se ha comentado mucho, el jueves 23 de abril hizo otras declaraciones confusas y peligrosas sobre el uso de rayos ultravioletas e inyecciones de desinfectantes. Mientras tanto, con sus palabras y sus hechos, mantiene una postura de duda hacia la ciencia y manifiesta sus ganas de promover la reapertura de la economía en contra de los consejos epidemiológicos de su propio gobierno. Trump sostiene repetidamente que una vacuna contra el virus estará disponible antes del 3 de noviembre, la fecha de la elección presidencial, aunque los peritos del gobierno dicen que esto no se puede asegurar. Aquí Trump demuestra escuetamente su capacidad de decir cualquier cosa para sobrevivir políticamente.

Lejos de liderar una respuesta coordinada entre el gobierno nacional y los estados, que tienen - para bien o para mal - mucha autonomía en asuntos de salud pública, Trump se pone a luchar con ciertos gobernadores (del Partido Demócrata, por cierto), y trata de socavar su autoridad, sumándose a las manifestaciones a favor de "liberar" la sociedad de las medidas restrictivas para controlar la pandemia. Trump le encargó a Jared Kushner, su yerno e integrante del entorno más íntimo del presidente, concebir el plan del gobierno nacional para controlar la pandemia, a pesar de su falta absoluta de experiencia en la salud pública. Como revela otra investigación periodística, Kushner determinó que un plan coordinado a nivel nacional era innecesario por razones políticas; ya que el covid-19 afectaba inicialmente los estados con gobernadores del Partido Demócrata (como Andrew Cuomo, de Nueva York, por ejemplo), a ellos les echaría la culpa (Eban, 30 jul. 2020). Por eso, la cuestión de nuestro sistema federalista de gobierno parece ser solo un pretexto conveniente; en realidad, Trump "eligió" una estrategia en la que el gobierno nacional renuncia a sus responsabilidades.

No es que Trump se equivoque siempre; el problema, en realidad, es que a veces él tiene razón. Claro, cuando una persona se contradice constantemente como Trump, algunas aclaraciones son falsas y otras verdaderas; dentro de un diluvio de mentiras, se filtran a veces verdades. Este fenómeno produce un efecto raro en sus opositores (sumamos muchos): sostenemos incoherencias solo para evitar estar de acuerdo con Trump. 
Un ejemplo puntual: Trump ha cuestionado la relación entre la OMS y el gobierno de China. Según él, la OMS perdió tiempo en los primeros días de la epidemia, dejándose engañar por el gobierno chino, que ocultaba el alcance y ferocidad verdaderos del virus. Su cuestionamiento levanta una buena pregunta, y merece investigación - una paciente y metódica investigación. Proponemos hacerla más tarde, luego que pase la emergencia sanitaria mundial. Para Trump, la investigación es una herramienta demasiado sofisticada; y mantener relaciones diplomáticas y multilaterales durante una emergencia internacional, no es tan importante. Su respuesta fue entonces radical, primero cortar toda la contribución de los EEUU al presupuesto de la OMS, y luego proclamar la desvinculación completa del país con la organización.

En política doméstica, el efecto colateral de esta maniobra, es de poner a los progresistas en la posición de defender la OMS y el gobierno de China. Esta postura los lleva a hacer declaraciones dudosas, como por ejemplo, que la OMS es una organización exclusivamente científica, cuando claramente tiene una racionalidad política. De nuevo, se nota el genio político de Trump (y de sus asesores): el sentimiento anti-Trump en este país es tan fuerte que anula todo razonamiento frío de la situación actual.

Esta polarización política también impacta las medidas sanitarias. En particular, el uso de mascarillas, conocido como una medida razonable para disminuir la transmisión del virus, se ha convertido en una cuestión de identidad política. Trump y sus defensores en los medios conservadores rechazan las mascarillas como una violación de la libertad individual. Las normativas de mascarillas quedan entonces muy heterogéneas; varían no solo de un estado al otro, sino de una ciudad a otra. De hecho, en julio el gobernador de Georgia, Brian Kemp (Republicano), demandó a la alcaldesa de Atlanta, Keisha Lance Bottoms (Demócrata), porqué esta ciudad sí hizo obligatorio el uso de mascarillas en lugares públicos (luego el gobernador se rindió y abandonó el pleito) (Cole, 13 ago. 2020). Dada esta falta de coherencia política, muchas compañías con alcance nacional (como Wal-Mart y Target) decidieron obligar el uso de mascarillas dentro de sus negocios, lo cual parece razonable y prudente, pero al mismo tiempo fortalece una tendencia fuerte de la cultura nacional: que la iniciativa privada, no el gobierno, puede resolver nuestros problemas colectivos. A este panorama hay que sumar los trastornos sociales del último verano luego del homicidio de George Floyd por oficiales de policía en Minnesota. Nuevamente, lejos de unir y calmar al pueblo, Trump fomenta el racismo y la rabia, lo que produce más conflicto e incertidumbre durante una pandemia.

Así llegamos a esta situación. Por lejos, somos el país con más casos y muertes de covid-19. En este momento - a principios de septiembre 2020 - hay más de 175 mil muertos en el país. Mientras en otros países el público aguantó medidas fuertes por un tiempo definido para luego salir a una fase segura de reapertura de negocios y escuelas, aquí ese proceso es caótico y sin coordinación.

Muchos que observan nuestra situación política desde afuera hacen una pregunta clave llena de incertidumbre: ¿Cómo puede ser que el pueblo lo apoye? Lamentablemente, no puedo responder bien a esta interrogante. Lo que sí puedo decir definitivamente es que no tiene el respaldo ahora de la mayoría del pueblo. En realidad, nunca lo tuvo. Igual, por el sistema político que tenemos no hace falta ganar una mayoría del voto popular 
para seguir siendo presidente. Debido a este sistema, su estrategia electoral es dividir y conquistar, y el clima de miedo e incertidumbre producido por la pandemia, todo es posible. Trump cuestiona la legitimidad de la votación por correo, herramienta necesaria dadas las condiciones impuestas por la pandemia. Aparentemente, le está restando recursos al Correo Nacional (US Postal Service), quizás para aumentar la confusión y desconfianza en nuestras instituciones (y sin duda, es una maniobra ajustada a la lógica privatizadora de este gobierno) (Berman, 21 ago. 2020).

Más recientemente, en una serie de entrevistas con el conocido periodista Bob Woodward, Trump confirmó que minimizaba el peligro del covid-19 públicamente, aunque estaba bien informado de su letalidad desde principios de febrero (Haberman, 9 sep. 2020). Quién sabe cuántas vidas se habrían salvado y cuánto daño económico se habría evitado con otro discurso al público y una postura seria y honesta frente la epidemia? En este momento precisamos el liderazgo de alguien con un mínimo sentido de humanidad. En cambio, lo que tiene el país es una acefalía moral en la presidencia.

\section{NOTA}

* El siguiente texto es una versión más completa, actualizada y sometida a revisión de pares de un post que apareció en el blog de História, Ciências, Saúde - Manguinhos.

\section{REFERENCIAS}

APPEL, Jacob M. Where's Trump's bioethics commission? The Baltimore Sun, 31 mayo 2019. Disponible en: <https://www.baltimoresun. com/opinion/op-ed/bs-ed-op-0603-bioethicscommission-20190531-story.html>. Acceso en: 25 abr. 2020.

BERMAN, Russell. The question at the heart of the Postal Service crisis. The Atlantic Online, 21 ago. 2020. Disponible en: $<$ https://www.theatlantic.com/ politics/archive/2020/08/postal-service-electiontrump-dejoy/615562>. Acceso en: 26 ago. 2020.

COLE, Devan. Georgia governor withdraws lawsuit challenging Atlanta mayor's mask mandate. CNN.com, 13 ago. 2020. Disponible en: <https:// www.cnn.com/2020/08/13/politics/brian-kempatlanta-mask-lawsuit-withdrawing/index.html >. Acceso en: 28 ago. 2020.

EBAN, Katherine. How Jared Kushner's secret testing plan 'went poof into thin air'. Vanity Fair, 30 jul. 2020. Disponible en: <https://www.vanityfair. com/news/2020/07/how-jared-kushners-secrettesting-plan-went-poof-into-thin-air>. Acceso en: 28 ago. 2020.

ENRÍQUEZ, Mariana. ¿Hay qué opinar sobre la pandemia? La ansiedad. Pagina 12, 18 abr. 2020. Disponible en: <https://www.pagina12.com. ar/260465-la-ansiedad>. Acceso en: 30 abr. 2020.
HABERMAN, Maggie. Trump admits downplaying the virus knowing it was 'deadly stuff'. New York Times, 9 sep. 2020. Disponible en: <https://www. nytimes.com/2020/09/09/us/politics/woodwardtrump-book-virus.html>. Acceso en: 11 sep. 2020. ROGERS, Katie; SHEAR, Michael D.; KANNOYOUNGS, Zolan. Trump plans to suspend immigration to US. New York Times, 20 abr. 2020. Disponible en: <https://www.nytimes. com/2020/04/20/us/politics/trump-immigration. html>. Acceso en: 25 abr. 2020.

SELLERS, Christopher et al. An embattled landscape series, part 2a: Coronavirus and the three-year Trump quest to slash science at the CDC. EDGI: Environmental Data and Governance Initiative, 2020. Disponible en: <https://envirodatagov.org/anembattled-landscape-series-part-2a-coronavirusand-the-three-year-trump-quest-to-slash-scienceat-the-cdc>. Acceso en: 25 abr. 2020.

SIMMONS-DUFFIN, Selena. Trump is trying hard to thwart Obamacare. How's that going? NPR News, 14 oct. 2019. Disponible en: <https://www.npr. org/sections/health-shots/2019/10/14/768731628/ trump-is-trying-hard-to-thwart-obamacare-howsthat-going >. Acceso en: 25 abr. 2020.

SUN, Lena H. Top White House official in charge of pandemic response resigns abruptly. Washington 
Post, 10 mayo 2018. Disponible en: <https:// www.washingtonpost.com/news/to-your-health/ $\mathrm{wp} / 2018 / 05 / 10 /$ top-white-house-official-incharge-of-pandemic-response-exits-abruptly>. Acceso en: 25 abr. 2020.
YONG, Ed. How the pandemic defeated America. The Atlantic Online, 4 ago. 2020. Disponible en: <https://www.theatlantic.com/magazine/ archive/2020/09/coronavirus-americanfailure/614191>. Acceso en: 20 ago. 2020.

\section{$\rightarrow \rightarrow \rightarrow<<<$}

